\title{
The Antiproliferative and Apoptotic Effect of a Novel Synthesized $S$-Triazine Dipeptide Series, and Toxicity Screening in Zebrafish Embryos
}

\author{
Azizah M. Malebari ${ }^{1}$, Rakia Abd Alhameed ${ }^{2}$, Zainab Almarhoon 2 ${ }^{\mathbb{D}}$, Muhammad Farooq ${ }^{3, * \mathbb{D} \text {, }}$ \\ Mohammad A. M. Wadaan ${ }^{3,4}$, Anamika Sharma ${ }^{5,6}{ }^{(D}$, Beatriz G. de la Torre ${ }^{5,6} \mathbb{D}$, Fernando Albericio ${ }^{2,6,7,8, *} \mathbb{D}$ \\ and Ayman El-Faham 2,9,*(D)
}

Citation: Malebari, A.M.; Abd Alhameed, R.; Almarhoon, Z.; Farooq M.; Wadaan, M.A.M.; Sharma, A.; de la Torre, B.G.; Albericio, F.; El-Faham,

A. The Antiproliferative and

Apoptotic Effect of a Novel

Synthesized S-Triazine Dipeptide Series, and Toxicity Screening in Zebrafish Embryos. Molecules 2021,

26, 1170. https://doi.org/10.3390/ molecules 26041170

Academic Editor: Helen Osborn

Received: 5 February 2021

Accepted: 18 February 2021

Published: 22 February 2021

Publisher's Note: MDPI stays neutral with regard to jurisdictional claims in published maps and institutional affiliations.

Copyright: (c) 2021 by the authors Licensee MDPI, Basel, Switzerland This article is an open access article distributed under the terms and conditions of the Creative Commons Attribution (CC BY) license (https:// creativecommons.org/licenses/by/ $4.0 /)$.
1 Department of Pharmaceutical Chemistry, College of Pharmacy, King Abdulaziz University, Jeddah 21589, Saudi Arabia; amelibary@kau.edu.sa

2 Department of Chemistry, College of Science, King Saud University, P.O. Box 2455, Riyadh 11451, Saudi Arabia; Roki.ahmed@yahoo.com (R.A.A.); zalmarhoon@ksu.edu.sa (Z.A.)

3 Bio-Products Research Chair, Department of Zoology, College of Science, King Saud University, P.O. Box 2455, Riyadh 11451, Saudi Arabia; Wadaan@ksu.edu.sa

4 Deanship of Postgraduate Studies and Scientific Research, Almaarefa University, Riyadh 11597, Saudi Arabia

5 KwaZulu-Natal Research Innovation and Sequencing Platform (KRISP), School of Laboratory Medicine and Medical Sciences, College of Health Sciences, University of KwaZulu-Natal, Durban 4041, South Africa; anamika.aug14@gmail.com (A.S.); garciadelatorreb@ukzn.ac.za (B.G.d.1.T.)

6 Peptide Science Laboratory, School of Chemistry and Physics, University of KwaZulu-Natal, Durban 4001, South Africa

7 CIBER-BBN (Networking Centre on Bioengineering, Biomaterials and Nanomedicine) and Department of Organic Chemistry, University of Barcelona, 08028 Barcelona, Spain

8 Institute for Advanced Chemistry of Catalonia (IQAC-CSIC), 08034 Barcelona, Spain

9 Chemistry Department, Faculty of Science, Alexandria University, P.O. Box 426, Ibrahimia, Alexandria 12321, Egypt

* Correspondence: fmuhammad@ksu.edu.sa (M.F.); albericio@ukzn.ac.za (F.A.); aelfaham@ksu.edu.sa (A.E.-F.); Tel.: +009-6611-467-3195 (A.E.-F.)

\begin{abstract}
Several derivatives containing morpholine/piperidine, anilines, and dipeptides as pending moieties were prepared using s-triazine as a scaffold. These compounds were evaluated for their anticancer activity against two human breast cancer cell lines (MCF-7 and MDA-MB-231), a colon cancer cell line (HCT-116), and a non-tumorigenic cell line (HEK 293). Tamoxifen was used as a reference. Animal toxicity tests were carried out in zebrafish embryos. Most of these compounds showed a higher activity against breast cancer than colon cancer. Compound 3a-which contains morpholine, aniline, and glycylglycinate methyl ester-showed a high level of cytotoxicity against MCF-7 cells with $\mathrm{IC}_{50}$ values of less than $1 \mu \mathrm{M}$. This compound showed a much lower level of toxicity against the non-tumorigenic HEK-293 cell line, and in the in vivo studies using zebrafish embryos. Furthermore, it induced cell cycle arrest at the G2/M phase, and apoptosis in MCF-7 cells. On the basis of our results, 3 a emerges as a potential candidate for further development as a therapeutic drug to treat hormone receptor-positive breast cancer.
\end{abstract}

Keywords: s-triazine; dipeptides; anti-proliferative activity; apoptosis; zebrafish

\section{Introduction}

Cancer is one of the most threatening diseases for human health. The identification of efficient therapeutic agents to treat this condition is a major objective in medicinal chemistry. Amongst women, breast cancer is considered the most malignant type. Moreover, it is not uncommon for patients to be diagnosed simultaneously with colorectal cancer [1] New anticancer therapeutic agents should be selective for cancer cells while exerting a lesser or no effect on normal cells [2-4]. In order to evaluate the medicinal value of any 
new compound, it is crucial to determine its biological activity before it can be considered further as a potential drug. Cell-based assays testing the cell viability, cell proliferation, and cytotoxicity are the main and primary steps in the drug discovery process. Among the drugs tested in vitro, only about $2 \%$ are approved for clinical trials, but even these may fail in preclinical animal assays [5]. Consequently, testing the safety of newly-synthesized compounds in suitable animal models before clinical trials is an essential step to save time and money. In this regard, zebrafish models have emerged in recent decades for such preclinical testing [6]. Given the reproducibility of the results, zebrafish models are expected to play a key role in speeding up the development of precision medicine [6-9].

In medicinal chemistry research, cyanuric chloride (trichlorotriazine (TCT)) became a privileged scaffold $[10,11]$ due to its availability and its selective reactivity under a controlled temperature [12,13].

In this regard, the three $\mathrm{Cl}$ atoms can be easily and independently substituted by a variety of nucleophiles in order to render a large number of substituted triazine derivatives. The convenient preparation of these derivatives has allowed their screening against several biological targets. These studies have revealed s-triazine as an outstanding core to build diverse pharmacophores. As such, trisubstituted s-triazine derivatives show numerous biological activities of interest: antimicrobial [14], anticancer [15,16], antitubercular [17], and anti-Human Immunodeficiency Virus anti-HIV [18], as well as inhibitory activity against human monoamine oxidase inhibitors (MAOIs) [19]. Additionally, it is important to highlight several $s$-triazine derivatives with morpholine moieties which show good biological activities, namely BKM-120, I [20], ZSTK474, II [21], and BMCL-200908069-1, III [22], three anticancer agents that have reached phase III clinical trials (Figure 1).<smiles>Nc1cc(C(F)(F)F)c(-c2nc(N3CCOCC3)nc(N3CCOCC3)n2)cn1</smiles>

I<smiles>FC(F)c1nc2ccccc2n1-c1nc(N2CCOCC2)nc(N2CCOCC2)n1</smiles>

II<smiles>COc1cc(/C=N/Nc2nc(N3CCOCC3)nc(N3CCOCC3)n2)cc(OC)c1O</smiles>

BMCL-200908069-1

Figure 1. Anticancer s-triazine drugs (I-III) in phase III clinical trials.

Given the above data and our ongoing efforts in the design and synthesis of novel antitumor agents using the s-triazine scaffold [11,14-16,23], here we have focused on the preparation of different $s$-triazine dipeptide (IV) derivatives (Figure 2) as modulators of biological activity. The synthesized analogs contain one piperidine/morpholine moiety and one aniline derivative in the other two positions, respectively, which have been previously shown to be important for biological activity. The compounds were evaluated against two human breast cancer cell lines (MCF-7 and MDA-MB-231), one colon cancer cell line (HCT116), and one non-tumorigenic human embryonic kidney cell line (HEK293). Furthermore, the toxicity of the compounds was also further tested in zebrafish embryos. 


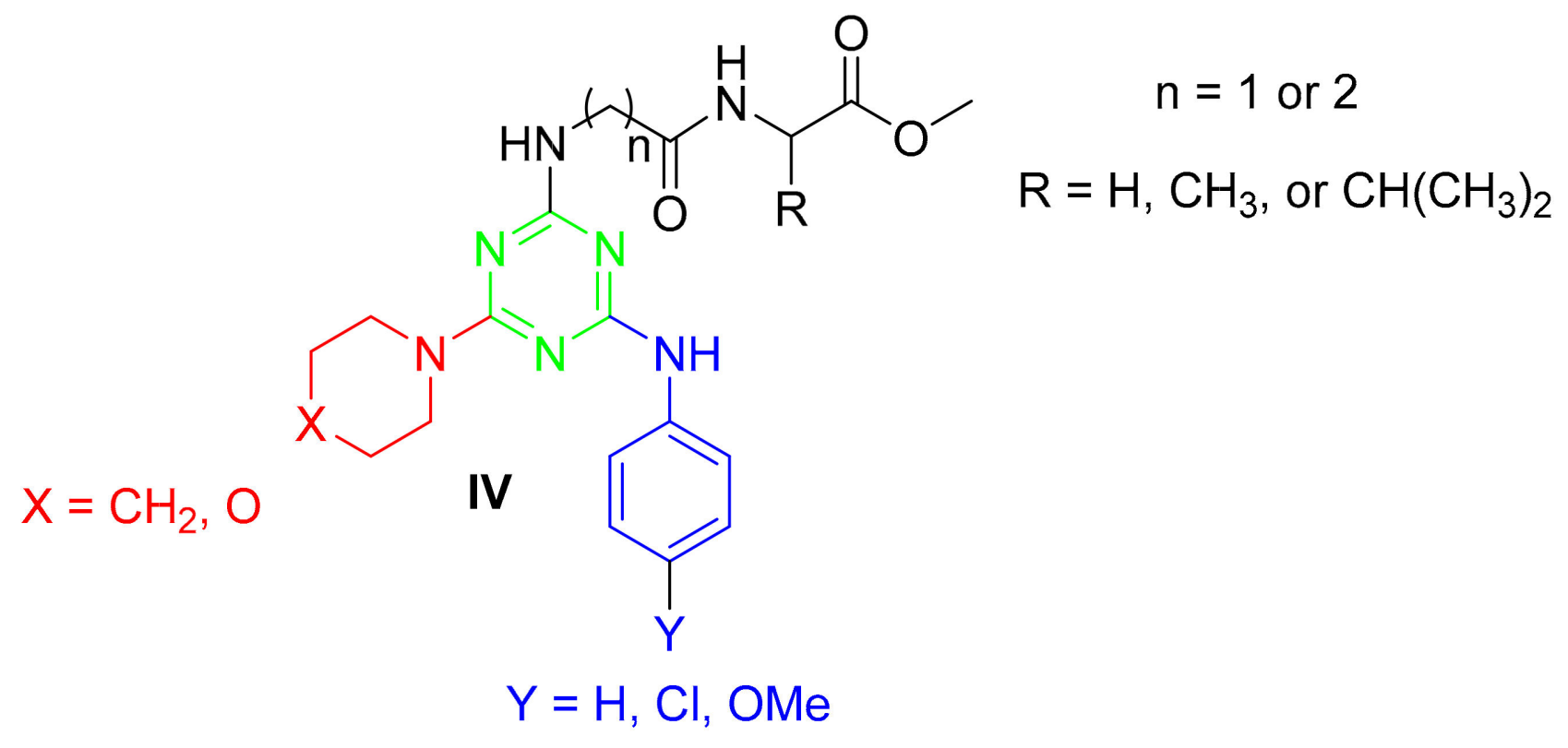

Figure 2. The target s-triazinyl dipeptide derivatives.

\section{Results and Discussion}

\subsection{Chemistry}

The key intermediates-namely 4,6-disubstituted s-triazin-2-yl amino acid derivatives 1-were prepared via a one-pot synthetic strategy using trichloro-s-triazine (TCT) under a controlled temperature, as previously reported by our group [14]. Briefly, TCT was left to react with different nucleophiles at different temperatures, without the isolation of the intermediates. First, the amino acid (Gly or $\beta$-Ala) (1 eq.) was added to the TCT using aq. $\mathrm{NaHCO}_{3}$ (2.2 eq.) as a base, at $0{ }^{\circ} \mathrm{C}$. After $2 \mathrm{~h}$ of reaction, aniline derivatives (1 eq.) were added in the presence of extra aq. $\mathrm{NaHCO}_{3}(1.2 \mathrm{eq}$,$) , and the reaction was left to react$ overnight at room temperature. Finally, the secondary amine (morpholine or piperidine) (1.1 eq.) was added in the presence of $N, N$-diisopropylethylamine (DIEA), and the mixture was refluxed in tetrahydrofuran (THF) for $24 \mathrm{~h}$ in order to render $\mathbf{1}$ in high purity and yield.

The product 1 was reacted with different amino acid methyl ester hydrochloride derivatives (Glycine, Alanine, Valine) 2 using $N, N^{\prime}$-diisopropylcarbodiimide (DIC) and ethyl 2-cyano-2-(hydroxyimino)acetate (OxymaPure) as the coupling method [24] in $\mathrm{N}, \mathrm{N}$ dimethylformamide (DMF) as a solvent and DIEA as a base, in order to give the target products 3a-o (Scheme 1) in high yield and purity. The spectral data confirmed the structures of the target products (Supplementary Materials, Figures S1-S15).

\subsection{Biology}

\subsubsection{Antiproliferative Activity}

The antiproliferative activity of the synthesized compounds was evaluated by the 3-(4,5-dimethylthiazol-2-yl)-2,5-diphenyl tetrazolium bromide (MTT) cell viability assay. Two types of breast cancer cell lines-namely MCF-7, which has estrogen and progesterone receptors, and MDA-MB-231, which is triple negative-were used, in addition to a colon cancer cell line (HCT-116). All of the compounds showed an antiproliferative effect against MCF-7, while their activity was slightly lower against MDA-MB-231, and only some of them were active against HCT-116 (Table 1). Overall, the morpholine-containing compounds tended to show greater activity than the piperidine-containing compounds in the MCF-7 cell line. In this regard, it is important to highlight compound 3a, the activity of which was below $\mu \mathrm{M}$. As a whole, this compound-which contains morpholino, aniline, and glycinyglycinate as pending moieties of the s-triazine ring-was one of the most active in the three cell lines, showing better activity than tamoxifen, which is an estrogen receptor 
<smiles>[R2]c1nc([R])nc(NCC(=O)O)n1</smiles>

1

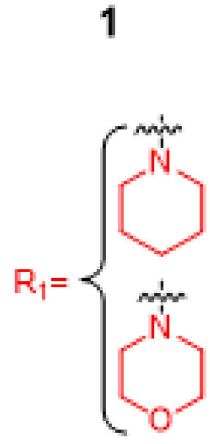

modulator, and has been used as a standard drug in this study $[25,26]$. Furthermore, $\mathbf{3 1}, \mathbf{3 n}$, and 30 also showed low $\mu \mathrm{M}$ activity against the MCF-7 cell line, and good activity against MDA-MB-231 and HCT-116 cells.<smiles>[R]C(N)C(=O)OC</smiles>

DMF

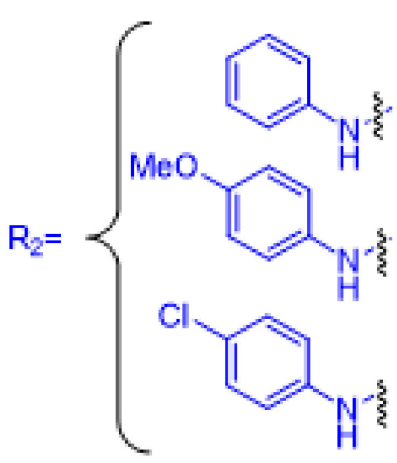<smiles>[R]c1nc([R2])nc(NCC(=O)NC([R3])C(=O)OC)n1</smiles>

$3 a-0$

\begin{tabular}{|c|c|c|c|c|}
\hline Compd & $\mathrm{R}_{1}$ & $\mathbf{R}_{2}$ & $n$ & $\mathrm{R}_{\mathbf{s}}$ \\
\hline $3 a$ & \multirow[t]{7}{*}{ morpholine } & $\mathrm{C}_{6} \mathrm{H}_{5}-\mathrm{NH}-$ & 1 & $\mathrm{H}$ \\
\hline $3 \mathbf{b}$ & & $4-\mathrm{Cl}-\mathrm{C}_{6} \mathrm{H}_{4}-\mathrm{NH}-$ & 1 & $\mathrm{H}$ \\
\hline $3 \mathrm{c}$ & & $4-\mathrm{OM} \mathrm{e}-\mathrm{Ca} \mathrm{H}_{4}-\mathrm{NH}_{-}$ & 1 & $\mathrm{H}$ \\
\hline $3 d$ & & $\mathrm{O}_{4} \mathrm{H}_{5}-\mathrm{NH}-$ & 1 & $\mathrm{CH}_{3}$ \\
\hline $3 \mathrm{e}$ & & 4-Cl- $\mathrm{C}_{4} \mathrm{H}_{4}-\mathrm{NH}-$ & 1 & $\mathrm{CH}_{3}$ \\
\hline $3 f$ & & 4-OMe- $\mathrm{C}_{6} \mathrm{H}_{4}-\mathrm{NH}-$ & 1 & $\mathrm{CH}_{3}$ \\
\hline $3 g$ & & $4-\mathrm{Cl}-\mathrm{CaH}_{4}-\mathrm{NH}-$ & 1 & $\mathrm{CH}\left(\mathrm{CH}_{3}\right)_{2}$ \\
\hline 3h & \multirow[t]{5}{*}{ piperidine } & $\mathrm{C}_{0} \mathrm{H}_{5}-\mathrm{NH}-$ & 1 & $\mathrm{H}$ \\
\hline $3 \mathrm{i}$ & & 4-Cl- $\mathrm{C}_{6} \mathrm{H}_{4}-\mathrm{NH}-$ & 1 & $\mathrm{H}$ \\
\hline $3 \mathrm{j}$ & & 4-OM e- $-\mathrm{C}_{4} \mathrm{H}_{4}-\mathrm{NH}-$ & 1 & $\mathrm{H}$ \\
\hline $3 \mathrm{k}$ & & $\mathrm{CaH}_{5}-\mathrm{NH}-$ & 1 & $\mathrm{CH}_{3}$ \\
\hline आ & & 4-Cl-CaH4- $-\mathrm{NH}_{4}-$ & 1 & $\mathrm{CH}_{3}$ \\
\hline $3 \mathrm{~m}$ & morpholine & 4-Cl- $\mathrm{C}_{4} \mathrm{H}_{4}-\mathrm{NH}-$ & 2 & $\mathrm{H}$ \\
\hline $3 n$ & morpholine & 4-Cl- $\mathrm{C}_{4} \mathrm{H}_{4}-\mathrm{NH}-$ & 2 & $\mathrm{CH}\left(\mathrm{CH}_{3}\right)_{2}$ \\
\hline 30 & piperidine & $4-\mathrm{Cl}-\mathrm{CeH}-\mathrm{NH}-$ & 2 & $\mathrm{CH}\left(\mathrm{CH}_{3}\right)_{2}$ \\
\hline
\end{tabular}

Scheme 1. Synthesis of 4,6-disubstituted s-triazine dipeptide ester derivatives 3a-o. 
Table 1. Antiproliferative effects of 3a-o in MCF-7, MDA-MB-231 and HCT-116 cells.

\begin{tabular}{cccc}
\hline \multirow{2}{*}{ Compound } & \multicolumn{3}{c}{ IC $_{\mathbf{5 0}}(\boldsymbol{\mu M})$} \\
\cline { 2 - 4 } & MCF-7 & MDA-MB-231 & HCT-116 \\
\hline 3a & $0.82 \pm 0.37$ & $9.36 \pm 1.15$ & $17.89 \pm 3.74$ \\
3b & $6.18 \pm 0.46$ & $>50$ & $>50$ \\
3c & $13.50 \pm 1.01$ & $>50$ & $>50$ \\
3d & $3.57 \pm 0.81$ & $16.25 \pm 0.63$ & $>50$ \\
3e & $4.35 \pm 2.86$ & $8.20 \pm 1.68$ & $>50$ \\
3f & $8.02 \pm 0.50$ & $28.07 \pm 1.07$ & $>50$ \\
3g & $13.24 \pm 0.60$ & $24.13 \pm 2.61$ & $12.19 \pm 1.74$ \\
3h & $19.64 \pm 0.08$ & $>50$ & $15.22 \pm 2.04$ \\
3i & $8.37 \pm 0.77$ & $22.26 \pm 1.87$ & $18.46 \pm 1.45$ \\
3j & $25.29 \pm 2.75$ & $>50$ & $23.36 \pm 3.43$ \\
3k & $15.31 \pm 2.49$ & $13.26 \pm 1.12$ & $>50$ \\
31 & $1.46 \pm 0.69$ & $8.31 \pm 0.69$ & $7.06 \pm 0.27$ \\
3m & $19.73 \pm 1.48$ & $26.66 \pm 1.32$ & $>50$ \\
3n & $2.35 \pm 1.06$ & $8.48 \pm 1.71$ & $14.38 \pm 1.37$ \\
3o & $4.64 \pm 1.58$ & $15.71 \pm 2.21$ & $18.93 \pm 2.82$ \\
Tamoxifen & $5.12 \pm 0.36$ & $15.01 \pm 0.12$ & $26.41 \pm 4.11$ \\
\hline
\end{tabular}

Additional assays were run with $\mathbf{3 a}$, the most promising compound. Its toxicity was evaluated using HEK-293 (normal human embryonic kidney), which is a non-tumorigenic cell line. The $\mathrm{IC}_{50}$ value of $3 \mathbf{a}$ was $>50 \mu \mathrm{M}$, a value that was significantly higher than that observed against the cancer cell lines MCF-7, MDA-MB-231 and HCT-116 (Figure 3). Therefore, this observation demonstrates that $\mathbf{3 a}$ is effectively selective for cancer cells, and causes less toxicity to normal human cells.

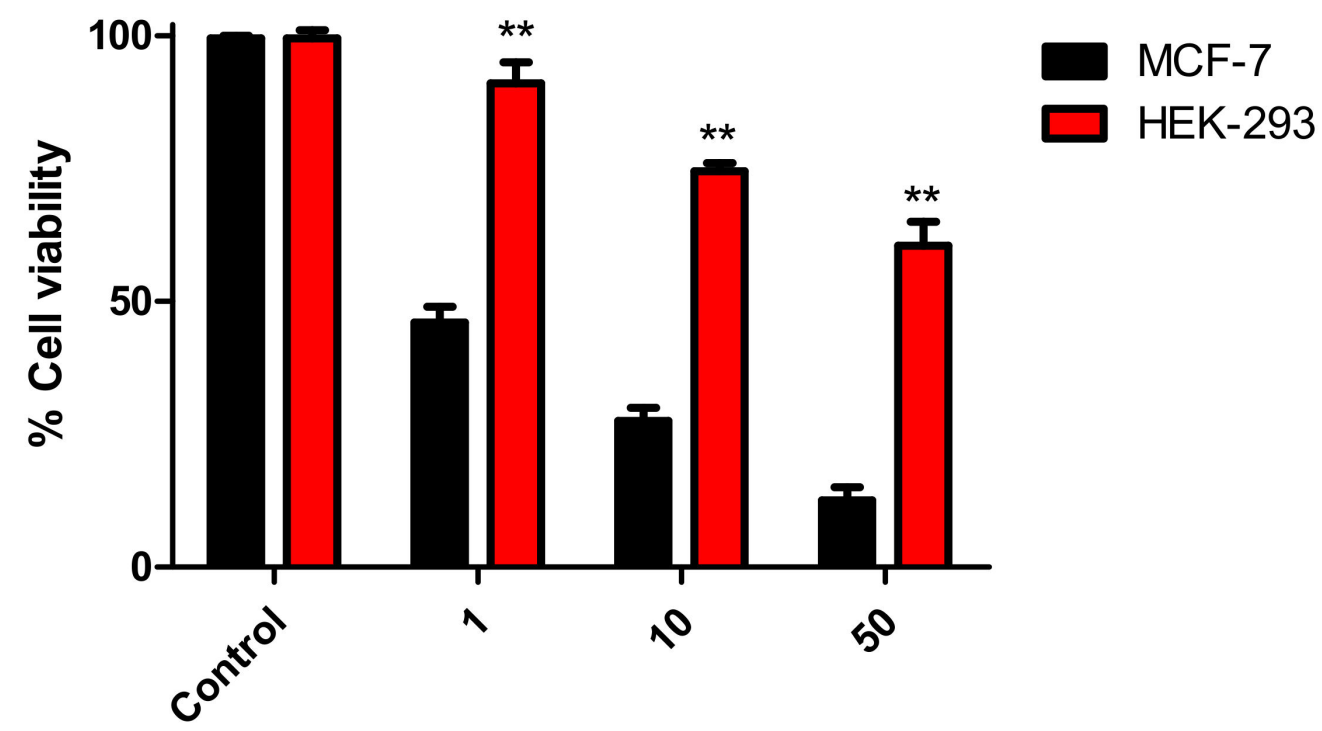

Concentration $(\mu \mathrm{M})$

Figure 3. The effect of compound 3a on the proliferation of breast cancer MCF-7 cells and normal HEK-293 cells. The cells were treated at a concentration of 1,10 or $50 \mu \mathrm{M}$ for $72 \mathrm{~h}$. The statistical analysis was performed using a one-way ANOVA-Bonferroni post-hoc test $(* *, p<0.01)$.

\subsubsection{Effects on the Cell Cycle Distribution and Apoptosis Assay}

The mechanism underlying the growth-inhibitory effect of 3a was further examined. The effect of 3a on cell cycle events in MCF-7 cells, after incubation at $2 \mu \mathrm{M}$ for $48 \mathrm{~h}$, was analyzed by a DNA flow cytometry assay of propidium iodide (PI) staining (Figure 4A). 
Compound 3a induced a statistically significant arrest of MCF-7 cells in the G2/M stage $(36.8 \%)$ compared to the untreated cell line (11.5\%) (Figure 4B). Moreover, the number of cells in the sub-G1 phase increased dramatically, from $3.7 \%$ (control) to $17.3 \%$.
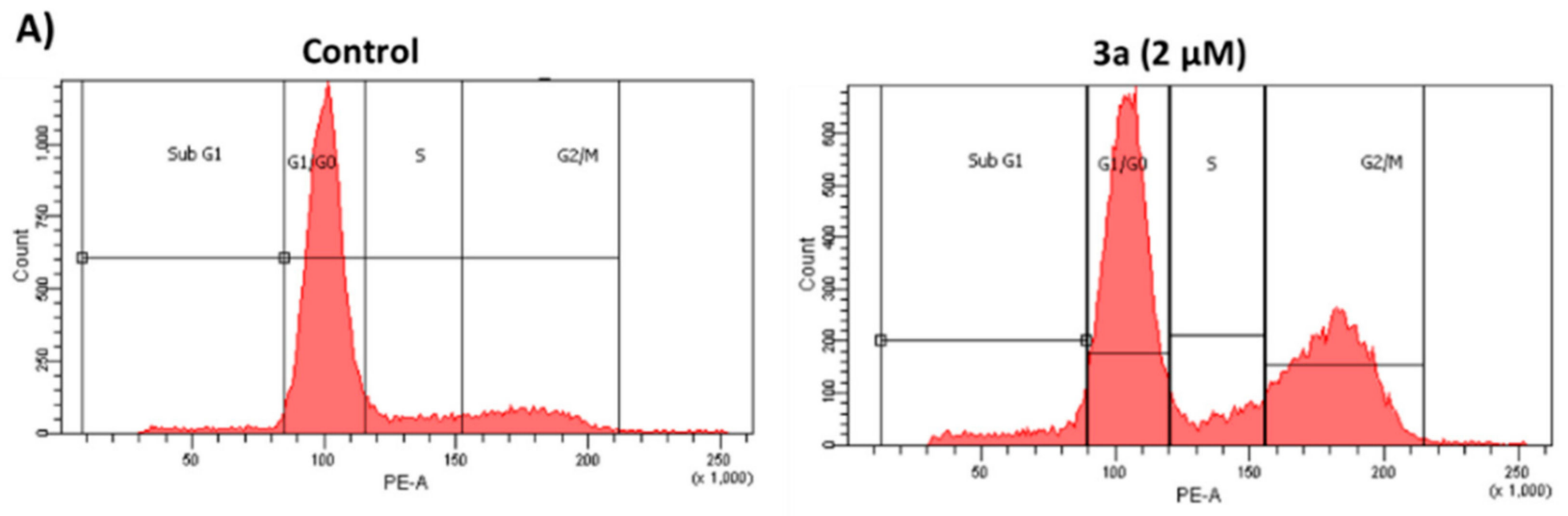

B)

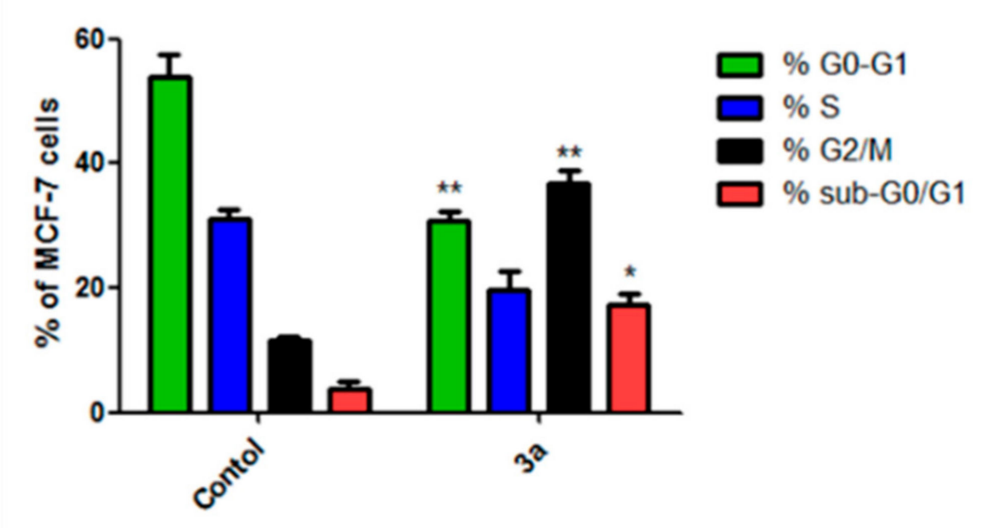

Figure 4. (A) Effect of compound 3a on the cell cycle and apoptosis in breast cancer MCF-7 cells. The cells were treated with either a vehicle $(0.1 \%$ ethanol $(v / v))$ or $3 \mathbf{a}(2 \mu \mathrm{M})$ for $48 \mathrm{~h}$. The cell cycle analysis was performed on histograms of gated counts per DNA area (FL2-A). (B) Quantitative analysis of 4N (G2/M), 2N (G0G1), >2N (S) and <2N (sub-G1). The DNA content was determined with CellQuest software. The values represent the mean $\pm \mathrm{SEM}$ for three independent experiments. The statistical analysis was performed using a one-way ANOVA-Bonferroni post-hoc test $\left.{ }^{*}, p<0.05 ;{ }^{* *}, p<0.01\right)$.

In order to determine the capacity of compound 3a to induce apoptosis, an Annexin V-FITC/PI dual staining assay was performed on the MCF-7 cells by flow cytometry. At $2 \mu \mathrm{M}$, this compound induced both early and late apoptosis in MCF-7 cells when compared to the untreated control cells (Figure 5A). In the control cells, the average proportion of Annexin V-positive cells (total apoptotic cells) increased from 8.3\% to 37.4\% (Figure 5B). These results revealed that the MCF-7 cells treated with 3a were arrested at the G2/M phase, and induced mainly cell apoptosis.

\subsubsection{In Vivo Evaluation in Zebrafish}

The cytotoxicity of compounds 3a-o was screened in zebrafish embryos. Compounds $\mathbf{3 a}, \mathbf{3 b}, \mathbf{3} \mathbf{c}$, and $\mathbf{3 d}$ did not show any toxicity in the zebrafish assay and were well tolerated even at the maximum concentration tested $(1 \mathrm{mM})$, where no significant difference in terms of mortality was observed with respect to DMSO as the control (Table 2). 
A)
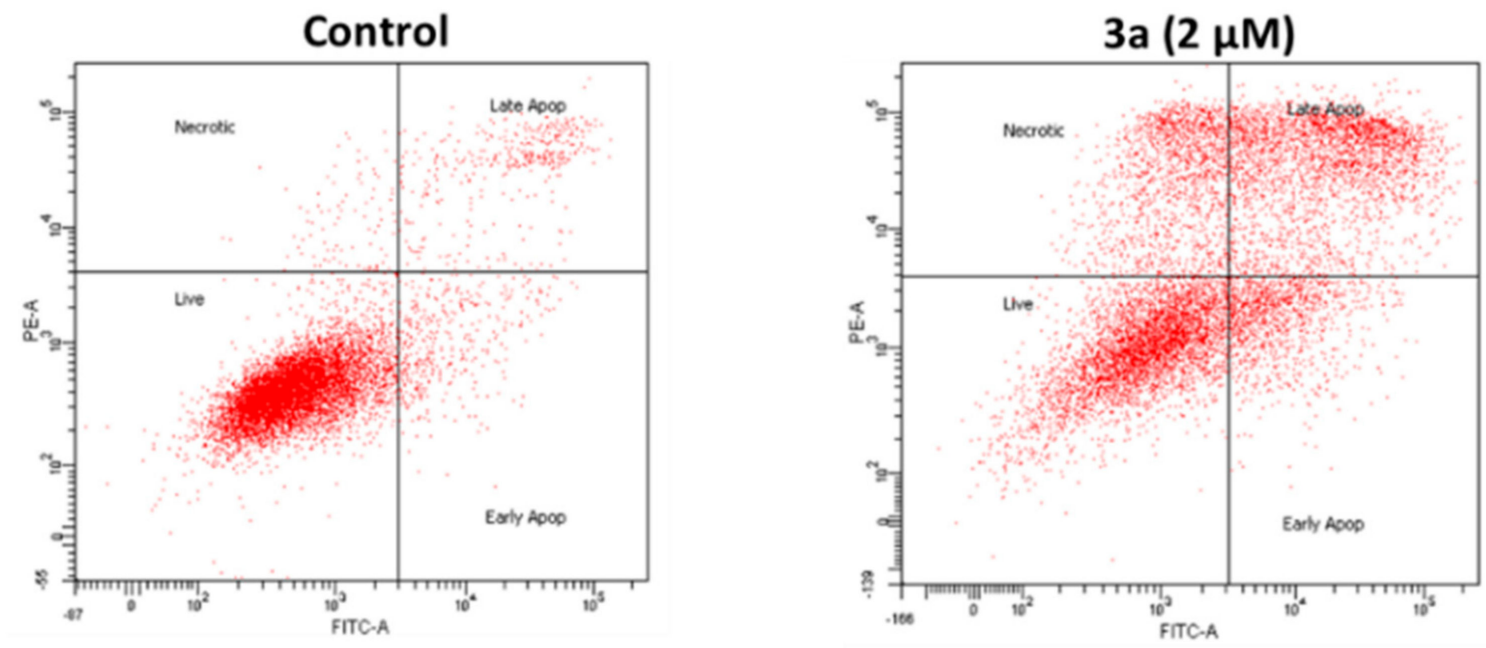

B)

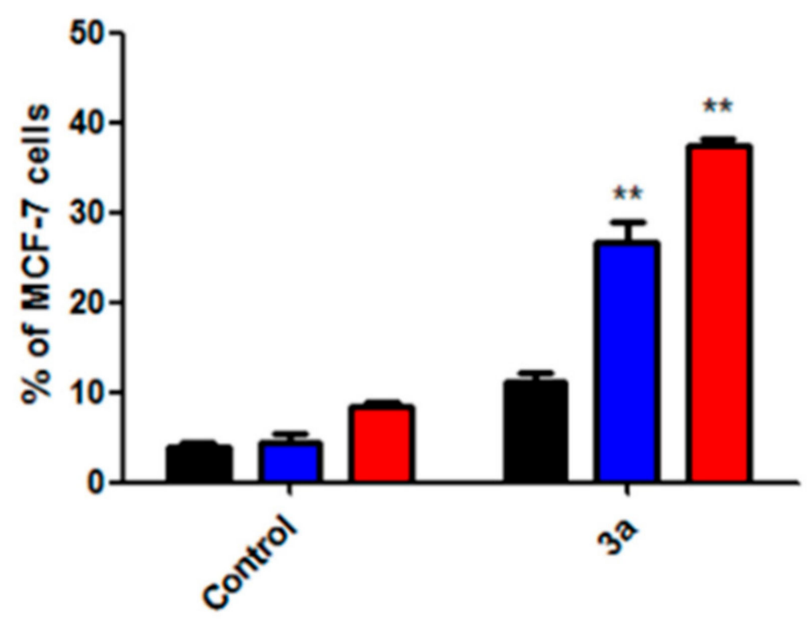

Early apoptosis

Late apoptosis

$\square$ Total apoptosis

Figure 5. Compound 3a potently induces apoptosis in breast cancer MCF-7 cells (Annexin V/PI Fluorescence-activated cell sorting (FACS)). (A) Flow cytometry analysis of the effect of compound 3a on MCF-7 cells. The MCF-7 cells were treated with $2 \mu \mathrm{M}$ of compound $3 \mathrm{a}$ for $48 \mathrm{~h}$, and then collected and processed for analysis. (B) The quantitative analysis of the apoptosis. The values represent the mean \pm SEM (Standard error of means) for three independent experiments. The statistical analysis was performed using a one-way ANOVA-Bonferroni post-hoc test $(* *, p<0.01)$. The four quadrants are identified as follows: lower left (LL), viable; Lower right (LR), early apoptotic; Upper right (UR), late apoptotic; and Upper left (UL), necrotic.

Table 2. Mortality response of zebrafish embryos to exposure to $\mathbf{3 a - 0 .}$

\begin{tabular}{cccc}
\hline Compound & ${ }^{*} \mathbf{L C}_{\mathbf{5 0}}(\boldsymbol{\mu M})$ & Compound & ${ }^{*} \mathbf{L C}_{\mathbf{5 0}}(\boldsymbol{\mu M})$ \\
\hline 3a & NA & $\mathbf{3 i}$ & $6.22 \pm 0.39$ \\
3b & NA & $\mathbf{3 j}$ & $80.15 \pm 0.59$ \\
3c & NA & $\mathbf{3 k}$ & $5.98 \pm 0.53$ \\
3d & NA & $3 \mathbf{l}$ & $4.25 \pm 0.38$ \\
3e & $2.37 \pm 0.27$ & $\mathbf{3 m}$ & $5.58 \pm 0.95$ \\
3f & $28.36 \pm 1.18$ & $\mathbf{3 n}$ & $5.84 \pm 1.09$ \\
3g & $132.14 \pm 0.86$ & $\mathbf{3 o}$ & $1.97 \pm 0.27$ \\
3h & $10.08 \pm 0.43$ & Tamoxifen & $8.00 \pm 0.95$
\end{tabular}

${ }^{*}$ Mean of three biological replicates \pm standard deviation. NA: no mortality was observed at or above a concentration of $1 \mathrm{mM}$. 
Moreover, the images of the zebrafish embryos at $48 \mathrm{hpf}$ (high power field) did not show any abnormality and/or morphological difference with respect to the non-treated embryos (Figure 6). In contrast, the zebrafish embryos treated with $10 \mu \mathrm{M}$ tamoxifen showed a severe teratogenic effect. The treated embryos had cardiac edema, craniofacial defects, tail lesions, and a delay in embryonic development. These observations are consistent with the findings in the literature $[27,28]$. Of note, $3 \mathbf{a}$, which was the compound that showed the greatest capacity to inhibit MCF-7 cell proliferation, did not show any toxicity.
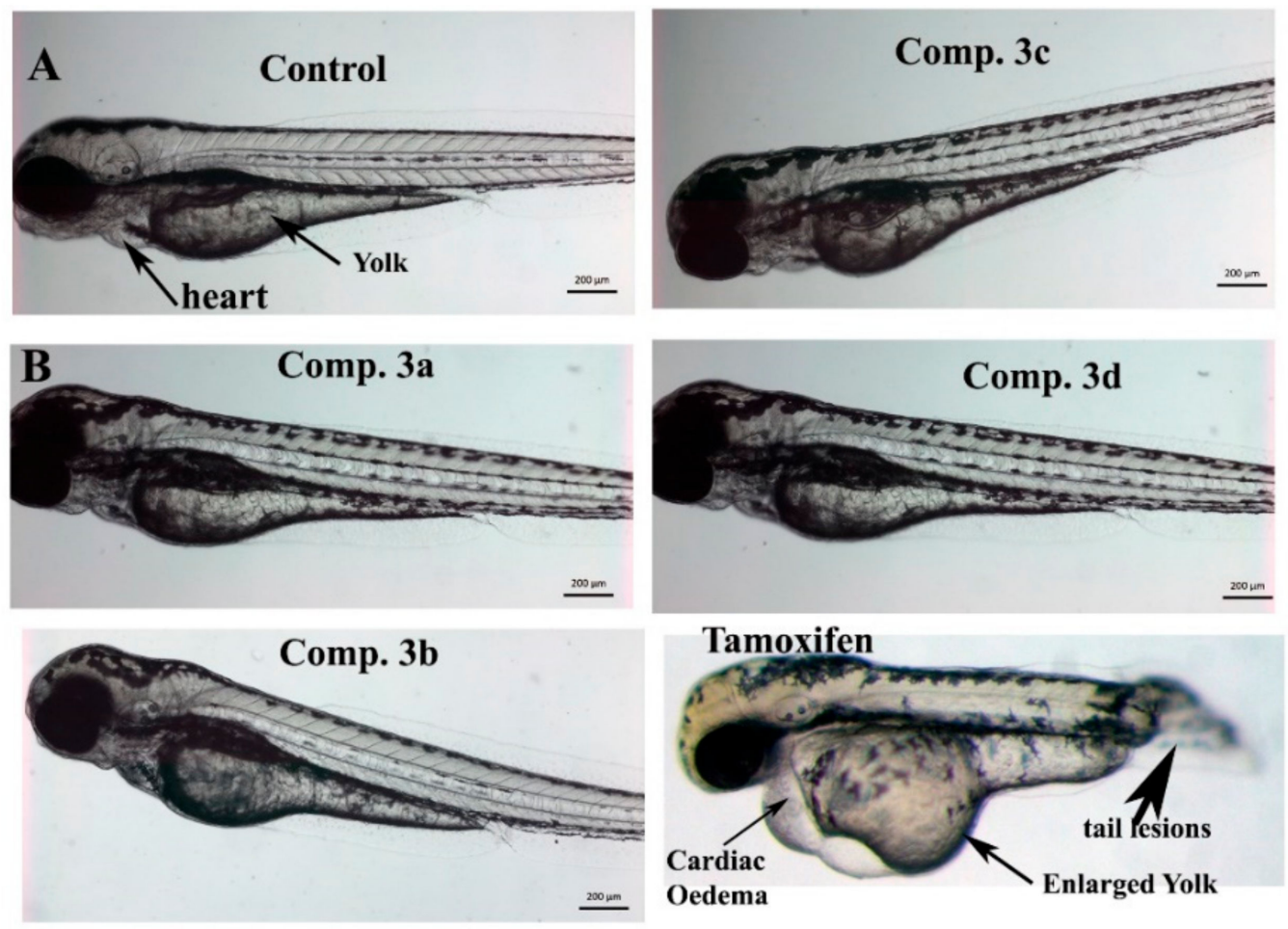

Figure 6. Representative images of the zebrafish embryos $48 \mathrm{hpf}(\mathbf{A})$ control or (B) treated. Zebrafish embryos shown are treated with $1 \mathrm{mM}$ of compounds $\mathbf{3 a}, \mathbf{3 b}, \mathbf{3} \mathbf{c}, \mathbf{3 d}$, and $10 \mu \mathrm{M}$ tamoxifen.

\section{Materials and Methods}

\subsection{Materials and Methods}

All of the reagents, chemicals and solvents were purchased from commercial suppliers. The reactions were monitored using TLC (silica gel 60-F254 protected aluminum sheets). The melting points were ascertained in open capillary tubes using a Gallenkamp melting point apparatus (Sigma-Aldrich Chemie GmbH, Taufkirchen, Germany), and were uncorrected. The Fourier transform infrared spectroscopy (FTIR) spectra were recorded on a Nicolet 6700 (Thermo Electron Scientific Instruments Corporation, Madison, WI, USA) spectrometer using $\mathrm{KBr}$ discs. The ${ }^{1} \mathrm{H}$ and ${ }^{13} \mathrm{C}$-NMR spectra were recorded on a VarianAgilent-NMR 600 MHz spectrometer (Varian, Inc., Palo Altro, CA, USA). The elemental analyses were recorded on a Perkin-Elmer 2400 elemental analyzer (PerkinElmer Inc. Waltham, MA, USA). The ultrasonic bath was purchased from Selecta (Barcelona, Spain). The experiments were performed in a multimode reactor (Monowave 300, Aton Paar $\mathrm{GmbH}, 1400 \mathrm{~W}$ maximum magnetron, Germany). The heat time ( $\left.5 \mathrm{~min}, 70^{\circ} \mathrm{C}, 350 \mathrm{watt}\right)$ and reaction time (hold time) were $12-15 \mathrm{~min}$ at identical wattages and temperatures, with stirring (800 rpm) and cooling until $25^{\circ} \mathrm{C}$. 


\subsection{Chemistry}

3.2.1. General Procedure for the Synthesis of the 4,6-Disubstituted s-Triazin-2-yl Amino Acid Derivatives

The 4,6-Disubstituted-s-triazin-2-amino acid derivatives 1 were reported in our previous work [14].

\subsubsection{General Method for the Synthesis of the 4,6-Disubstituted s-Triazine}

Dipeptide tDerivatives

A mixture of an acid $1(1 \mathrm{mmol})$ and OxymaPure $(1 \mathrm{mmol})$ was dissolved in $5 \mathrm{~mL}$ DMF at $0{ }^{\circ} \mathrm{C}$, followed by the dropwise addition of DIC $(1.1 \mathrm{mmol})$ at $0{ }^{\circ} \mathrm{C}$, with pre-activation for $5 \mathrm{~min}$. The amino acid ester hydrochloride $2(1 \mathrm{mmol})$ was then added dropwise at the same temperature, in the presence of diisopropylethylamine (DIEA, $1 \mathrm{mmol}$ ) as a base. After that, the mixture was stirred at $0{ }^{\circ} \mathrm{C}$ for $1 \mathrm{~h}$, and then left overnight under stirring at room temperature. The progress of the reaction was monitored by TLC $\left(\mathrm{CH}_{2} \mathrm{Cl}_{2}\right.$-hexane; 4:6). Excess water was added when a precipitate formed. The final product was isolated by filtration, and washed with water. If the precipitate did not form, the mixture underwent extraction, washing and drying with ethyl acetate, with $1 \mathrm{~N} \mathrm{HCl}$ and a saturated solution of $\mathrm{Na}_{2} \mathrm{CO}_{3}$ and $\mathrm{NaCl}$, followed by drying over anhydrous $\mathrm{MgSO}_{4}$ in order to obtain the target product.

Methyl (4-morpholino-6-(phenylamino)-1, 3, 5-triazin-2-yl) glycylglycinate (3a). A white powder in a $90 \%$ yield, mp $195-197^{\circ} \mathrm{C}$. IR $\left(\mathrm{KBr}, \mathrm{cm}^{-1}\right)$ : 3374, $3315(\mathrm{NH}), 1728,1652(\mathrm{CO}) .{ }^{1} \mathrm{H}-\mathrm{NMR}$ (DMSO- $\left.d_{6}, \mathrm{ppm}\right): \delta 3.60\left(7 \mathrm{H}, \mathrm{brs}, \mathrm{CH}_{2}-\mathrm{O}-\mathrm{CH}_{2}, \mathrm{COOCH}_{3}\right), 3.67\left(4 \mathrm{H}, \mathrm{t} J=4.2,4.8 \mathrm{~Hz}, \mathrm{CH}_{2}-\right.$ $\left.\mathrm{N}-\mathrm{CH}_{2}\right), 3.83-3.91\left(4 \mathrm{H}, \mathrm{m}, \mathrm{CH}_{2} \mathrm{CONHCH}_{2} \mathrm{CO}\right), 6.89(1 \mathrm{H}, \mathrm{t}, J=7.2,7.8, \mathrm{Ar}-\mathrm{H}), 7.21(2 \mathrm{H}, \mathrm{t}$, $J=7.8,8.4 \mathrm{~Hz}, \mathrm{Ar}-\mathrm{H}), 7.69(2 \mathrm{H}, \mathrm{dd}, J=7.2 \mathrm{~Hz}, \mathrm{Ar}-\mathrm{H}), 7.12(1 \mathrm{H}, \mathrm{s}, \mathrm{NH}), 8.20(1 \mathrm{H}, \mathrm{d}, \mathrm{NH})$, $9.04(1 \mathrm{H}, \mathrm{d}, \mathrm{NH}) ;{ }^{13} \mathrm{C}-\mathrm{NMR}$ (DMSO- $\left.d_{6}, \mathrm{ppm}\right): \delta 41.1,43.7,44.1,52.1,66.5,119.9,121.7$, $128.7,140.9,164.5,165.1,166.2,170.7,170.9$. Analysis calculated for $\mathrm{C}_{18} \mathrm{H}_{23} \mathrm{~N}_{7} \mathrm{O}_{4}$ (401.43): C, 53.86; H, 5.78; N, 24.43. Found C, 53.99; H, 5.85; N, 24.61.

Methyl (4-((4-chlorophenyl) amino)-6-morpholino-1, 3, 5-triazin-2-yl) glycylglycinate (3b). A white powder in a $90 \%$ yield, $\mathrm{mp} 227-229^{\circ} \mathrm{C}$. IR $\left(\mathrm{KBr}, \mathrm{cm}^{-1}\right): 3375,3313(\mathrm{NH}), 1724,1654$ (CO). ${ }^{1} \mathrm{H}-\mathrm{NMR}$ (DMSO-d $\left.d_{6}, \mathrm{ppm}\right): \delta 3.58\left(3 \mathrm{H}, \mathrm{s}, \mathrm{COOCH}_{3}\right), 3.60\left(4 \mathrm{H}, \mathrm{brs}, \mathrm{CH}_{2}-\mathrm{N}_{-} \mathrm{CH}_{2}\right), 3.66$ $\left(4 \mathrm{H}, \mathrm{m}, J=4.2 \mathrm{~Hz}, \mathrm{CH}_{2}-\mathrm{O}-\mathrm{CH}_{2}\right), 3.83-3.89\left(4 \mathrm{H}, \mathrm{m}, 2 \mathrm{CH}_{2}\right), 7.19(1 \mathrm{H}, \mathrm{s}, \mathrm{NH}), 7.26(2 \mathrm{H}, \mathrm{d}$, $J=8.4 \mathrm{~Hz}, \mathrm{Ar}-\mathrm{H}) 7.72(2 \mathrm{H}, \mathrm{dd}, J=7.2,8.4 \mathrm{~Hz}, \mathrm{Ar}-\mathrm{H}), 8.21(1 \mathrm{H}, \mathrm{d}, \mathrm{NH}), 9.21(1 \mathrm{H}, \mathrm{d}, \mathrm{NH})$; ${ }^{13} \mathrm{C}-\mathrm{NMR}$ (DMSO- $d_{6}, \mathrm{ppm}$ ): $\delta 41.1,43.7,44.1,52.1,66.4,121.5,125.2,128.6,140.0,164.3$, 165.0, 166.1, 170.7, 170.8. Analysis calculated for $\mathrm{C}_{18} \mathrm{H}_{22} \mathrm{ClN}_{7} \mathrm{O}_{4}$ (435.87): $\mathrm{C}, 49.60 ; \mathrm{H}, 5.09$; N, 22.50. Found C, 49.83; H, 5.21; N, 22.77.

Methyl (4-((4-methoxyphenyl) amino)-6-morpholino-1, 3, 5-triazin-2-yl) glycylglycinate (3c). A white powder in a $90 \%$ yield, $\mathrm{mp} 209-211^{\circ} \mathrm{C}$. IR $\left(\mathrm{KBr}, \mathrm{cm}^{-1}\right): 3374,3310(\mathrm{NH}), 1724,1654$ (CO). ${ }^{1} \mathrm{H}-\mathrm{NMR}$ (DMSO- $\left.d_{6}, \mathrm{ppm}\right): \delta 3.59\left(7 \mathrm{H}\right.$, brs, $\left.\mathrm{COOCH}_{3} \& \mathrm{CH}_{2}-\mathrm{O}-\mathrm{CH}_{2}\right), 3.65(4 \mathrm{H}, \mathrm{brs}$, $\left.\mathrm{CH}_{2}-\mathrm{N}-\mathrm{CH}_{2}\right), 3.68\left(3 \mathrm{H}, \mathrm{s},-\mathrm{OCH}_{3}\right), 3.82-3.88\left(4 \mathrm{H}, \mathrm{m}, 2 \mathrm{CH}_{2}\right), 6.80(2 \mathrm{H}, \mathrm{d}, J=7.8 \mathrm{~Hz}, \mathrm{Ar}-\mathrm{H})$, $7.55(2 \mathrm{H}, \mathrm{t}, J=8.4,13.8 \mathrm{~Hz}, \mathrm{Ar}-\mathrm{H}), 8.19(1 \mathrm{H}, \mathrm{s}, \mathrm{NH}), 8.89(1 \mathrm{H}, \mathrm{d}, \mathrm{NH}) ;{ }^{13} \mathrm{C}-\mathrm{NMR}$ (DMSO-d $d_{6}$, ppm): $\delta 41.0,43.7,44.1,52.1,55.6,66.5,114.0,121.6,134.0,154.6,164.3,165.1,166.1,170.8$, 170.9. Analysis calculated for $\mathrm{C}_{19} \mathrm{H}_{25} \mathrm{~N}_{7} \mathrm{O}_{5}$ (431.45): $\mathrm{C}, 52.89 ; \mathrm{H}, 5.84 ; \mathrm{N}, 22.73$. Found $\mathrm{C}$, 53.03; H, 5.95; N, 22.98.

Methyl (4-morpholino-6-(phenylamino)-1, 3, 5-triazin-2-yl) glycylalaninate (3d). A white powder in a $93 \%$ yield, mp $196-198{ }^{\circ} \mathrm{C}$. IR $\left(\mathrm{KBr}, \mathrm{cm}^{-1}\right)$ : 3400, $3281(\mathrm{NH}), 1740,1657(\mathrm{CO}) .{ }^{1} \mathrm{H}-\mathrm{NMR}$ (DMSO-d $\left.d_{6}, \mathrm{pmm}\right): \delta 1.25\left(3 \mathrm{H}, \mathrm{d}, J=7.2 \mathrm{~Hz}, \mathrm{NHCH}\left(\mathrm{CH}_{3}\right)\right), 3.57\left(3 \mathrm{H}, \mathrm{s}, \mathrm{COOCH}_{3}\right), 3.60(4 \mathrm{H}$, brs, $\left.\mathrm{CH}_{2}-\mathrm{O}-\mathrm{CH}_{2}\right), 3.66\left(4 \mathrm{H}, \mathrm{m}, \mathrm{CH}_{2}-\mathrm{N}-\mathrm{CH}_{2}\right), 3.80-3.93\left(2 \mathrm{H}, \mathrm{m}, \mathrm{CH}_{2}\right), 4.30(1 \mathrm{H}, \mathrm{t}, J=6.6$, $7.2 \mathrm{~Hz}, \mathrm{CH}), 6.89(1 \mathrm{H}, \mathrm{t}, J=7.2,7.8, \mathrm{NH}), 7.03(1 \mathrm{H}, \mathrm{m}, \mathrm{Ar}-\mathrm{H}), 7.21(2 \mathrm{H}, \mathrm{t}, J=7.8,8.4 \mathrm{~Hz}$, Ar-H), 7.69 (2H, dd, J = 8.4, 7.2 Hz, Ar-H), $8.26(1 \mathrm{H}, \mathrm{d}, \mathrm{NH}), 9.02(1 \mathrm{H}, \mathrm{d}, \mathrm{NH}) ;{ }^{13} \mathrm{C}-\mathrm{NMR}$ (DMSO- $d_{6}, \mathrm{ppm}$ ): $\delta 17.6,43.7,47.8,47.9,52.3,66.5,119.9,121.7,128.7,140.9,164.5,165.0$, 166.1, 170.0, 173.5. Analysis calculated for $\mathrm{C}_{19} \mathrm{H}_{25} \mathrm{~N}_{7} \mathrm{O}_{4}$ (415.45): $\mathrm{C}, 54.93 ; \mathrm{H}, 6.07 ; \mathrm{N}, 23.60$. Found C, 54.76; H, 6.19; N, 23.85. 
Methyl (4-((4-chlorophenyl) amino)-6-morpholino-1, 3, 5-triazin-2-yl) glycylalaninate (3e). A white powder in a $90 \%$ yield, mp $189-191^{\circ} \mathrm{C}$. IR $\left(\mathrm{KBr}, \mathrm{cm}^{-1}\right): 3408,3273(\mathrm{NH}), 1745,1659$ (CO). ${ }^{1} \mathrm{H}-\mathrm{NMR}$ (DMSO-d $\left.d_{6}, \mathrm{ppm}\right): \delta 1.25\left(3 \mathrm{H}, \mathrm{d}, J=6.6 \mathrm{~Hz}, \mathrm{CH}_{3}\right), 3.56-3.60\left(7 \mathrm{H}, \mathrm{m}, \mathrm{COOCH}_{3}\right.$ \& $\left.\mathrm{CH}_{2}-\mathrm{O}-\mathrm{CH}_{2}\right), 3.66\left(4 \mathrm{H}\right.$, brs, $\left.\mathrm{CH}_{2}-\mathrm{N}_{-} \mathrm{CH}_{2}\right), 3.79-3.82\left(2 \mathrm{H}, \mathrm{m}, \mathrm{CH}_{2}\right), 4.29(1 \mathrm{H}, \mathrm{q}, \mathrm{J}=6.6$, $7.2 \mathrm{~Hz}, \mathrm{CH}), 7.11(1 \mathrm{H}, \mathrm{s}, \mathrm{NH}), 7.25(2 \mathrm{H}, \mathrm{d}, J=8.4 \mathrm{~Hz}, \mathrm{Ar}-\mathrm{H}), 7.73(2 \mathrm{H}, \mathrm{dd}, J=7.2,8.4 \mathrm{~Hz}$, Ar-H), $8.26(1 \mathrm{H}, \mathrm{d}, \mathrm{NH}), 9.19(1 \mathrm{H}, \mathrm{d}, \mathrm{NH}) ;{ }^{13} \mathrm{C}-\mathrm{NMR}\left(\mathrm{DMSO}-d_{6}, \mathrm{ppm}\right): \delta 17.6,43.7,47.8$, $47.9,52.3,66.5,121.4,125.2,128.6,140.0,164.4,165.0,166.1,170.0,173.5$. Analysis calculated for $\mathrm{C}_{19} \mathrm{H}_{24} \mathrm{ClN}_{7} \mathrm{O}_{4}$ (449.90): C, 50.72; H, 5.38; N, 21.79. Found C, 50.54; H, 5.26; N, 21.99.

Methyl (4-((4-methoxyphenyl) amino)-6-morpholino-1, 3, 5-triazin-2-yl) glycylalaninate (3f). A white powder in a $90 \%$ yield, mp $191-193^{\circ} \mathrm{C}$. IR $\left(\mathrm{KBr}, \mathrm{cm}^{-1}\right): 3405,3286(\mathrm{NH}), 1742,1660$ (CO). ${ }^{1} \mathrm{H}-\mathrm{NMR}$ (DMSO-d $\left.d_{6}, \mathrm{ppm}\right): \delta 1.24\left(3 \mathrm{H}, \mathrm{d}, \mathrm{J}=7.2 \mathrm{~Hz}, \mathrm{CH}_{3}\right), 3.59\left(7 \mathrm{H}, \mathrm{brs}, \mathrm{CH}_{2}-\mathrm{O}-\mathrm{CH}_{2}\right.$ \& $\left.\mathrm{COOCH}_{3}\right), 3.65\left(4 \mathrm{H}\right.$, brs, $\left.\mathrm{CH}_{2}-\mathrm{N}-\mathrm{CH}_{2}\right), 3.68\left(3 \mathrm{H}, \mathrm{s},-\mathrm{OCH}_{3}\right) 3.77-3.80\left(2 \mathrm{H}, \mathrm{m}, \mathrm{CH}_{2}\right), 4.29$ $(1 \mathrm{H}, \mathrm{t}, J=6.6 \mathrm{~Hz}, \mathrm{CH}), 6.80(2 \mathrm{H}, \mathrm{d}, J=8.4 \mathrm{~Hz}, \mathrm{Ar}-\mathrm{H}), 7.56(2 \mathrm{H}, \mathrm{d}, J=7.8 \mathrm{~Hz}, \mathrm{Ar}-\mathrm{H}), 8.25(1 \mathrm{H}$, d, NH), $8.87(1 \mathrm{H}, \mathrm{d}, \mathrm{NH}) ;{ }^{13} \mathrm{C}-\mathrm{NMR}$ (DMSO- $\left.d_{6}, \mathrm{ppm}\right): \delta 17.6,43.7,47.8,47.9,52.3,55.6,66.5$, $114.0,121.6,134.0,154.6,164.4,166.1,170.1,173.5$. Analysis calculated for $\mathrm{C}_{20} \mathrm{H}_{27} \mathrm{~N}_{7} \mathrm{O}_{5}$ (445.48): C, 53.92; H, 6.11; N, 22.01. Found C, 54.01; H, 6.30; N, 22.27.

Methyl (4-((4-chlorophenyl) amino)-6-morpholino-1, 3, 5-triazin-2-yl) glycylvalinate (3g). A white powder in a $93 \%$ yield, $\mathrm{mp} 173-175^{\circ} \mathrm{C}$. IR $\left(\mathrm{KBr}, \mathrm{cm}^{-1}\right): 3406,3367,3306(\mathrm{NH}), 1727,1660$ (CO). ${ }^{1} \mathrm{H}-\mathrm{NMR}$ (DMSO-d 6 , ppm): $\delta 0.82\left(6 \mathrm{H}, \mathrm{dd}, J=6.6,10.8 \mathrm{~Hz}, 2 \mathrm{CH}_{3}\right), 2.00(1 \mathrm{H}, \mathrm{q}, J=6.6$, $7.2 \mathrm{~Hz}, \mathrm{CH}), 3.58\left(4 \mathrm{H}\right.$, brs, $\left.\mathrm{CH}_{2}-\mathrm{O}-\mathrm{CH}_{2}\right), 3.61\left(3 \mathrm{H}, \mathrm{s},-\mathrm{COOCH}_{3}\right), 3.66\left(4 \mathrm{H}, \mathrm{brs}, \mathrm{CH}_{2}-\mathrm{N}-\right.$ $\left.\mathrm{CH}_{2}\right), 3.83-3.89\left(2 \mathrm{H}, \mathrm{m}, \mathrm{CH}_{2}\right), 4.20(1 \mathrm{H}, \mathrm{m}, \mathrm{CH}), 7.25(2 \mathrm{H}, \mathrm{t}, J=7.8,8.4 \mathrm{~Hz}, \mathrm{Ar}-\mathrm{H}), 7.72(2 \mathrm{H}$, $\mathrm{dd}, J=8.4,7.2 \mathrm{~Hz}, \mathrm{Ar}-\mathrm{H}), 8.07(1 \mathrm{H}, \mathrm{d}, \mathrm{NH}), 9.18(1 \mathrm{H}, \mathrm{d}, \mathrm{NH}) ;{ }^{13} \mathrm{C}-\mathrm{NMR}$ (DMSO- $\left.d_{6}, \mathrm{ppm}\right)$ : $\delta 18.5,19.4,30.6,43.7,52.1,57.6,57.8,66.5,121.4,125.2,128.6,140.0,164.3,165.0,166.1,170.4$, 172.5. Analysis calculated for $\mathrm{C}_{21} \mathrm{H}_{28} \mathrm{ClN}_{7} \mathrm{O}_{4}$ (477.95): C, 52.77; $\mathrm{H}, 5.91 ; \mathrm{N}, 20.51$. Found $\mathrm{C}$, 52.54; H, 5.86; N, 20.76.

Methyl (4-(phenylamino)-6-(piperidin-1-yl)-1, 3, 5-triazin-2-yl) glycylglycinate (3h). A white powder in a $93 \%$ yield, mp 92-94 ${ }^{\circ} \mathrm{C}$. IR $\left(\mathrm{KBr}, \mathrm{cm}^{-1}\right): 3357(\mathrm{NH}), 1742,1660$ (CO). ${ }^{1} \mathrm{H}-\mathrm{NMR}$ (DMSO- $\left.d_{6}, \mathrm{ppm}\right): \delta 1.46\left(4 \mathrm{H}, \mathrm{brs}, 2 \mathrm{CH}_{2}\right), 1.59\left(2 \mathrm{H}, \mathrm{brs}, \mathrm{CH}_{2}\right), 3.59\left(3 \mathrm{H}, \mathrm{d}, \mathrm{COOCH}_{3}\right), 3.67$ $\left(4 \mathrm{H}\right.$, brs, $\left.\mathrm{CH}_{2}-\mathrm{N}-\mathrm{CH}_{2}\right), 3.82-3.90\left(4 \mathrm{H}, \mathrm{m}, 2 \mathrm{CH}_{2}\right), 6.88(1 \mathrm{H}, \mathrm{t}, J=7.8,7.2 \mathrm{~Hz}, \mathrm{Ar}-\mathrm{H}), 7.02(1 \mathrm{H}$, s, NH), $7.20(2 \mathrm{H}, \mathrm{t}, J=7.2 \mathrm{~Hz}, \mathrm{Ar}-\mathrm{H}), 7.69$ (2H, dd, $J=7.8,6.6 \mathrm{~Hz}, \mathrm{Ar}-\mathrm{H}), 8.19(1 \mathrm{H}, \mathrm{s}, \mathrm{NH})$, $8.95(1 \mathrm{H}, \mathrm{d}, \mathrm{NH}) ;{ }^{13} \mathrm{C}-\mathrm{NMR}$ (DMSO- $\left.d_{6}, \mathrm{ppm}\right): \delta 24.8,25.8,41.0,44.0,44.1,52.1,119.8,121.6$, $128.7,140.9,164.6,166.2,166.6,170.7,170.9$. Analysis calculated for $\mathrm{C}_{19} \mathrm{H}_{25} \mathrm{~N}_{7} \mathrm{O}_{3}(399.46)$ : C, 57.13; H, 6.31; N, 24.55. Found C, 56.89; H, 6.42; N, 24.78.

Methyl (4-((4-chlorophenyl) amino)-6-(piperidin-1-yl)-1, 3, 5-triazin-2-yl) glycylglycinate (3i). A white powder in a $91 \%$ yield, $\mathrm{mp} 172-174{ }^{\circ} \mathrm{C}$. IR $\left(\mathrm{KBr}, \mathrm{cm}^{-1}\right): 3428,3278(\mathrm{NH}), 1757,1658$ (CO). ${ }^{1} \mathrm{H}-\mathrm{NMR}$ (DMSO-d $d_{6}$ ppm): $\delta 1.45\left(4 \mathrm{H}, \mathrm{brs}, \mathrm{CH}_{2}\right), 1.59\left(2 \mathrm{H}, \mathrm{brs}, \mathrm{CH}_{2}\right), 3.59(3 \mathrm{H}, \mathrm{s}$, $\left.\mathrm{COOCH}_{3}\right), 3.67\left(4 \mathrm{H}, \mathrm{s}, \mathrm{CH}_{2}-\mathrm{N}-\mathrm{CH}_{2}\right), 3.82-3.87\left(4 \mathrm{H}, \mathrm{m}, \mathrm{CH}_{2}\right), 7.12(1 \mathrm{H}, \mathrm{s}, \mathrm{NH}), 7.25(2 \mathrm{H}, \mathrm{d}$, $J=8.4 \mathrm{~Hz}, \mathrm{Ar}-\mathrm{H}), 7.73(2 \mathrm{H}, \mathrm{dd}, J=6.6,7.2 \mathrm{~Hz}, \mathrm{Ar}-\mathrm{H}), 8.21(1 \mathrm{H}, \mathrm{s}, \mathrm{NH}), 9.14(1 \mathrm{H}, \mathrm{d}, \mathrm{NH})$; ${ }^{13}$ C-NMR (DMSO- $d_{6}$, ppm): $\delta 24.8,25.9,41.1,44.1,44.1,52.1,121.3,125.0,128.5,139.9,164.4$, 164.6, 166.1, 166.5, 170.9. Analysis calculated for $\mathrm{C}_{19} \mathrm{H}_{24} \mathrm{ClN}_{7} \mathrm{O}_{3}$ (433.90): C, 52.60; $\mathrm{H}, 5.58$; N, 22.60. Found C, 52.83; H, 5.67; N, 22.89.

Methyl (4-((4-methoxyphenyl) amino)-6-(piperidin-1-yl)-1, 3, 5-triazin-2-yl) glycylglycinate (3j). White powder in a $88 \%$ yield, mp $143-145^{\circ} \mathrm{C}$. IR $\left(\mathrm{KBr}, \mathrm{cm}^{-1}\right): 3402,3287(\mathrm{NH}), 1739,1664$ (CO). ${ }^{1} \mathrm{H}-\mathrm{NMR}$ (DMSO-d $\left.d_{6}, \mathrm{ppm}\right): \delta 1.45\left(4 \mathrm{H}, \mathrm{brs}, 2 \mathrm{CH}_{2}\right), 1.59\left(2 \mathrm{H}, \mathrm{brs}, \mathrm{CH}_{2}\right), 3.59(3 \mathrm{H}$, $\left.\mathrm{s}, \mathrm{COOCH}_{3}\right), 3.66\left(4 \mathrm{H}\right.$, brs, $\left.\mathrm{CH}_{2}-\mathrm{N}-\mathrm{CH}_{2}\right), 3.69\left(3 \mathrm{H}, \mathrm{s}, \mathrm{OCH}_{3}\right), 3.82-3.87\left(4 \mathrm{H}, \mathrm{m}, 2 \mathrm{CH}_{2}\right)$, $6.80(2 \mathrm{H}, \mathrm{d}, J=6.6 \mathrm{~Hz}, \mathrm{Ar}-\mathrm{H}), 6.96(1 \mathrm{H}, \mathrm{s}, \mathrm{NH}), 7.57(2 \mathrm{H}, \mathrm{t}, J=7.2,12.6 \mathrm{~Hz}, \mathrm{Ar}-\mathrm{H}), 8.18$ $(1 \mathrm{H}, \mathrm{s}, \mathrm{NH}), 8.80(1 \mathrm{H}, \mathrm{d}, \mathrm{NH}) ;{ }^{13} \mathrm{C}-\mathrm{NMR}\left(\mathrm{DMSO}-d_{6}, \mathrm{ppm}\right): \delta 24.9,25.8,41.0,44.0,44.2$, 52.1, 55.6, 113.9, 121.4, 134.0, 154.5, 164.4, 164.7, 166.2, 170.7, 171.0. Analysis calculated for $\mathrm{C}_{20} \mathrm{H}_{27} \mathrm{~N}_{7} \mathrm{O}_{4}$ (429.48): C, 55.93; H, 6.34; N, 22.83. Found C, 55.77; H, 6.50; N, 23.04.

Methyl (4-(phenylamino)-6-(piperidin-1-yl)-1, 3, 5-triazin-2-yl) glycylalaninate (3k). A white powder in a $90 \%$ yield, mp $176-178^{\circ} \mathrm{C}$. IR $\left(\mathrm{KBr}, \mathrm{cm}^{-1}\right): 3401,3287(\mathrm{NH}), 1741,1661(\mathrm{CO})$. ${ }^{1} \mathrm{H}-\mathrm{NMR}\left(\mathrm{DMSO}-\mathrm{d}_{6}, \mathrm{ppm}\right): \delta 1.25\left(3 \mathrm{H}, \mathrm{d}, \mathrm{J}=6.6 \mathrm{~Hz}, \mathrm{CH}_{3}\right), 1.46\left(4 \mathrm{H}, \mathrm{brs}, 2 \mathrm{CH}_{2}\right), 1.60(2 \mathrm{H}$, 
brs, $\left.\mathrm{CH}_{2}\right), 3.58\left(3 \mathrm{H}, \mathrm{s}, \mathrm{COOCH}_{3}\right), 3.68\left(4 \mathrm{H}, \mathrm{brs}, \mathrm{CH}_{2}-\mathrm{N}-\mathrm{CH}_{2}\right), 3.83\left(2 \mathrm{H}, \mathrm{m}, \mathrm{CH}_{2}\right), 4.29(1 \mathrm{H}, \mathrm{s}$, $\mathrm{CH}), 6.88(1 \mathrm{H}, \mathrm{t}, J=7.2,7.8 \mathrm{Ar}-\mathrm{H}), 7.20(2 \mathrm{H}, \mathrm{t}, J=7.8 \mathrm{~Hz}, \mathrm{Ar}-\mathrm{H}), 7.69(2 \mathrm{H}, \mathrm{dd}, J=7.2,7.8 \mathrm{~Hz}$, Ar-H), $6.93(1 \mathrm{H}, \mathrm{s}, \mathrm{NH}), 8.25(1 \mathrm{H}, \mathrm{d}, \mathrm{NH}), 8.93(1 \mathrm{H}, \mathrm{m}, \mathrm{NH}) .{ }^{13} \mathrm{C}-\mathrm{NMR}\left(\mathrm{DMSO}-d_{6}, \mathrm{ppm}\right)$ : $\delta$ 17.6, 24.8, 25.9, 44.0, 47.9, 52.3, 119.8, 121.6, 128.7, 141.1, 164.5, 164.6, 166.2, 170.1, 173.5 . Analysis calculated for $\mathrm{C}_{20} \mathrm{H}_{27} \mathrm{~N}_{7} \mathrm{O}_{3}$ (413.48): C, 58.10; $\mathrm{H}, 6.58 ; \mathrm{N}, 23.71$. Found $\mathrm{C}, 58.33 ; \mathrm{H}$, 6.64; N, 23.97.

Methyl (4-((4-chlorophenyl) amino)-6-(piperidin-1-yl)-1, 3, 5-triazin-2-yl) glycylalaninate (3l). A white powder in a $93 \%$ yield, mp $192-194{ }^{\circ} \mathrm{C}$. IR $\left(\mathrm{KBr}, \mathrm{cm}^{-1}\right): 3400,3291(\mathrm{NH}), 1745,1659$ (CO). ${ }^{1} \mathrm{H}-\mathrm{NMR}\left(\mathrm{DMSO}-d_{6}, \mathrm{ppm}\right): \delta 1.24\left(3 \mathrm{H}, \mathrm{t}, J=7.8,8.4 \mathrm{~Hz}, \mathrm{CH}_{3}\right), 1.45\left(4 \mathrm{H}, \mathrm{brs}, 2 \mathrm{CH}_{2}\right)$, $1.59\left(2 \mathrm{H}\right.$, brs, $\left.\mathrm{CH}_{2}\right), 3.58\left(3 \mathrm{H}, \mathrm{s}, \mathrm{COOCH}_{3}\right), 3.67\left(4 \mathrm{H}, \mathrm{s}, \mathrm{CH}_{2}-\mathrm{N}-\mathrm{CH}_{2}\right), 3.77-3.89\left(2 \mathrm{H}, \mathrm{m}, \mathrm{CH}_{2}\right)$, $4.28(1 \mathrm{H}, \mathrm{q}, J=6.6,7.2 \mathrm{~Hz}, \mathrm{CH}), 7.02(1 \mathrm{H}, \mathrm{s}, \mathrm{NH}), 7.25(2 \mathrm{H}, \mathrm{d}, J=7.2 \mathrm{~Hz}, \mathrm{Ar}-\mathrm{H}), 7.74(2 \mathrm{H}$, $\mathrm{dd}, J=7.2,8.4 \mathrm{~Hz}, \mathrm{Ar}-\mathrm{H}), 8.27(1 \mathrm{H}, \mathrm{d}, \mathrm{NH}), 9.12(1 \mathrm{H}, \mathrm{d}, \mathrm{NH}) ;{ }^{13} \mathrm{C}-\mathrm{NMR}$ (DMSO- $\left.d_{6}, \mathrm{ppm}\right)$ : $\delta 17.6,24.8,25.9$, 44.0, 47.9, 47.9, 52.3, 121.3, 125.0, 128.5, 140.2, 164.4, 164.5, 166.1, 170.1, 173.4. Analysis calculated for $\mathrm{C}_{20} \mathrm{H}_{26} \mathrm{ClN}_{7} \mathrm{O}_{3}$ (447.92): C, 53.63; H, 5.85; N, 21.89. Found C, 53.85; H, 5.93; N, 21.65.

Methyl (3-((4-((4-chlorophenyl) amino)-6-morpholino-1, 3, 5-triazin-2-yl) amino) propanoyl) glycinate $(3 \mathrm{~m})$. A white powder in a $94 \%$ yield, $\mathrm{mp} 146-148{ }^{\circ} \mathrm{C}$. IR $\left(\mathrm{KBr}, \mathrm{cm}^{-1}\right): 3368(\mathrm{NH})$, $1726 \& 1678$ (CO). ${ }^{1} \mathrm{H}-\mathrm{NMR}$ (DMSO- $\left.d_{6}, \mathrm{ppm}\right): \delta 2.42\left(2 \mathrm{H}, \mathrm{q}, J=7.2,7.8 \mathrm{~Hz}, \mathrm{CH}_{2}\right), 3.46$ $\left(2 \mathrm{H}, \mathrm{q}, J=6.6,7.2 \mathrm{~Hz}, \mathrm{CH}_{2}\right), 3.59\left(4 \mathrm{H}, \mathrm{m}, \mathrm{CH}_{2}-\mathrm{O}-\mathrm{CH}_{2}\right), 3.61\left(3 \mathrm{H}, \mathrm{s},-\mathrm{COOCH}_{3}\right), 3.66$ $\left(4 \mathrm{H}, \mathrm{m}, \mathrm{CH}_{2}-\mathrm{N}-\mathrm{CH}_{2}\right), 3.82\left(2 \mathrm{H}, \mathrm{d}, J=6.0 \mathrm{~Hz}, \mathrm{CH}_{2}\right), 6.88(1 \mathrm{H}, \mathrm{d}, \mathrm{NH}), 7.25(2 \mathrm{H}, \mathrm{t}, J=9.0$, $9.6 \mathrm{~Hz}, \mathrm{Ar}-\mathrm{H}), 7.75(2 \mathrm{H}, \mathrm{d}, J=7.8 \mathrm{~Hz}, \mathrm{Ar}-\mathrm{H}), 8.33(1 \mathrm{H}, \mathrm{s}, \mathrm{NH}), 9.16(1 \mathrm{H}, \mathrm{d}, \mathrm{NH}) ;{ }^{13} \mathrm{C}-\mathrm{NMR}$ (DMSO- $\left.d_{6}, \mathrm{ppm}\right): \delta 35.4,37.1,40.9,43.8,52.2,66.7,121.4,125.4,128.8,140.2,164.2,165.1$, 166.1, 171.0, 171.9. Analysis calculated for $\mathrm{C}_{19} \mathrm{H}_{24} \mathrm{ClN}_{7} \mathrm{O}_{4}$ (449.90): $\mathrm{C}, 50.72 ; \mathrm{H}, 5.38 ; \mathrm{N}$, 21.79. Found C, 50.93; H, 5.43; N, 21.96.

Methyl (3-((4-((4-chlorophenyl) amino)-6-morpholino-1, 3, 5-triazin-2-yl) amino) propanoyl) valinate (3n). A white powder in a $92 \%$ yield, $\mathrm{mp} 171-173^{\circ} \mathrm{C}$. IR $\left(\mathrm{KBr}, \mathrm{cm}^{-1}\right)$ : 3432, 3353, 3194, (NH), 1730, 1679 (CO). ${ }^{1} \mathrm{H}-\mathrm{NMR}$ (DMSO-d $\left.6, \mathrm{ppm}\right): \delta 0.84\left(6 \mathrm{H}, \mathrm{d}, J=7.2 \mathrm{~Hz}, \mathrm{CH}_{3} \mathrm{CHCH}_{3}\right)$, $1.98\left(1 \mathrm{H}, \mathrm{d}, J=6.0 \mathrm{~Hz}, \mathrm{CH}\left(\mathrm{CH}_{3}\right)_{2}\right), 2.47\left(2 \mathrm{H}, \mathrm{t}, J=5.4,9.0 \mathrm{~Hz}\right.$, triazine $\left.\mathrm{CH}_{2} \mathrm{CH}_{2} \mathrm{CONH}\right), 3.46$ $\left(2 \mathrm{H}, \mathrm{t}, J=5.4,6.6 \mathrm{~Hz}\right.$, triazine $\left.\mathrm{NHCH}_{2}\right), 3.59\left(3 \mathrm{H}, \mathrm{s}, \mathrm{COOCH}_{3}\right), 3.61-3.68\left(8 \mathrm{H}, \mathrm{m}, 4 \mathrm{CH}_{2}\right)$, $4.16(1 \mathrm{H}, \mathrm{d}, J=4.8 \mathrm{~Hz}, \mathrm{CH}), 6.86(1 \mathrm{H}, \mathrm{s}, \mathrm{NH}), 7.24(2 \mathrm{H}, \mathrm{d}, J=6.6 \mathrm{~Hz}, \mathrm{Ar}-\mathrm{H}), 7.75(2 \mathrm{H}, \mathrm{s}$, Ar-H), 8.17 (1H, m, NH), $9.17(1 \mathrm{H}, \mathrm{d}, \mathrm{NH}) ;{ }^{13} \mathrm{C}-\mathrm{NMR}$ (DMSO-d, ppm): $\delta 18.7,19.4,30.3$, 35.4, 37.2, 43.7, 52.1, 57.8, 66.5, 121.3, 125.2, 128.6, 140.0, 164.4, 165.8, 166.0, 171.6, 172.6. Analysis calculated for $\mathrm{C}_{22} \mathrm{H}_{30} \mathrm{ClN}_{7} \mathrm{O}_{4}$ (491.98): C, 53.71; $\mathrm{H}, 6.15 ; \mathrm{N}, 19.93$. Found C, 53.95; $\mathrm{H}, 6.32 ; \mathrm{N}, 19.77$.

Methyl (3-((4-((4-chlorophenyl) amino)-6-(piperidin-1-yl)-1, 3, 5-triazin-2- yl) amino) propanoyl) valinate (3o). A white powder in a $91 \%$ yield, $\mathrm{mp} 178-180{ }^{\circ} \mathrm{C}$. IR $\left(\mathrm{KBr}, \mathrm{cm}^{-1}\right)$ : 3436,3353 , 3194 (NH), $1730 \& 1678$ (CO). ${ }^{1} \mathrm{H}-\mathrm{NMR}$ (DMSO- $\left.d_{6}, \mathrm{ppm}\right): \delta 0.85\left(6 \mathrm{H}, \mathrm{d}, J=7.2 \mathrm{~Hz}, 2 \mathrm{CH}_{3}\right)$, 1.45(4H, brs, 2CH $), 1.59\left(2 \mathrm{H}\right.$, brs, $\left.\mathrm{CH}_{2}\right), 1.96-2.00(1 \mathrm{H}, \mathrm{m}, \mathrm{CH}), 2.45(2 \mathrm{H}, \mathrm{dd}, J=7.2,6.6 \mathrm{~Hz}$, $\left.\mathrm{CH}_{2}\right), 3.45\left(2 \mathrm{H}, \mathrm{s}, \mathrm{CH}_{2}\right), 3.61\left(3 \mathrm{H}, \mathrm{s}, \mathrm{COOCH}_{3}\right), 3.67\left(4 \mathrm{H}, \mathrm{d}, \mathrm{CH}_{2}-\mathrm{N}_{-} \mathrm{CH}_{2}\right), 4.16(1 \mathrm{H}, \mathrm{t}, J=6.6$, $7.2 \mathrm{~Hz}, \mathrm{CH}), 6.76(1 \mathrm{H}, \mathrm{d}, \mathrm{NH}), 7.24(2 \mathrm{H}, \mathrm{d}, J=7.8 \mathrm{~Hz}, \mathrm{Ar}-\mathrm{H}), 7.76(2 \mathrm{H}, \mathrm{s}, \mathrm{Ar}-\mathrm{H}), 8.17(1 \mathrm{H}, \mathrm{t}$, $\mathrm{NH}), 9.08$ (1H, d, NH); ${ }^{13} \mathrm{C}-\mathrm{NMR}$ (DMSO- $\left.d_{6}, \mathrm{ppm}\right): \delta 18.8,19.4,24.8,25.9,30.3,35.4,37.2$, $44.0,52.1,57.8,121.2,124.9,128.6,140.2,164.4,164.6,166.2,171.5,172.6$. Analysis calculated for $\mathrm{C}_{23} \mathrm{H}_{32} \mathrm{ClN}_{7} \mathrm{O}_{3}$ (490.01): C, 56.38; H, 6.58; N, 20.01. Found C, 56.14; H, 6.69; N, 20.28.

\subsection{Biology}

\subsubsection{MTT Cell Proliferation Assays}

The target products 3a-o were evaluated for their antiproliferative activity using the MTT viability assay of the MCF-7, MDA-MB-231 and HCT-116 cell lines (in triplicate) on at least three independent occasions for the determination of the reported mean values. 


\subsubsection{Cell Culture}

The three human tumor cell lines MCF-7, MDA-MB-231 and HCT-116 were cultured in Dulbecco's Modified Eagle's Medium (DMEM) with 10\% fetal bovine serum, $2 \mathrm{mM}$ L-glutamine and $100 \mu \mathrm{g} / \mathrm{mL}$ penicillin/streptomycin. The cells were maintained at $37^{\circ} \mathrm{C}$ in $5 \% \mathrm{CO}_{2}$ in a humidified incubator. All of the cells were sub-cultured 3 times/week by trypsinization using TrypLE Express $(1 \times)$.

\subsubsection{Cell Viability Assay}

In order to calculate the relative $\mathrm{IC}_{50}$ values, the antiproliferative effect of compounds 3a-o was tested in three cancer cell lines (MCF-7, MDA-MB-231, HCT-116) and normal epithelial embryonic kidney cells (HEK-293) using the MTT viability assay. The cells were seeded in 96-well plates at a density of $10 \times 10^{3}$ cells $/ \mathrm{mL}$, in a total volume of $200 \mu \mathrm{L}$ per well. In total, $0.1 \%$ DMSO was used as a vehicle control. After $24 \mathrm{~h}$, the cells were treated with $2 \mu \mathrm{L}$ of the test compound, which had been pre-prepared as a stock solution to furnish the concentration range of the study $(0.01-100 \mu \mathrm{M})$, and re-incubated for $72 \mathrm{~h}$. The culture medium was then removed, and the cells were washed with phosphate-buffered saline (PBS), and $100 \mu \mathrm{L}$ MTT was added (for a final concentration of $5 \mathrm{mg} / \mathrm{mL}$ MTT). The cells were incubated for $4 \mathrm{~h}$ in darkness at $37^{\circ} \mathrm{C}$. Next, $200 \mu \mathrm{L}$ DMSO was added to each well, and the cells were maintained at room temperature in darkness for $20 \mathrm{~min}$. The absorbance was detected with a microplate reader at $570 \mathrm{~nm}$. The results were expressed as a percentage of viability relative to the vehicle control $(100 \%)$. The dose-response curves were plotted, and the $\mathrm{IC}_{50}$ values were obtained using Prism software (GraphPad Software, Inc., La Jolla, CA, USA). All of the experiments were repeated in three independent experiments.

\subsubsection{Cell Cycle Analysis}

The MCF-7 cells were treated with compound 3a $(2 \mu \mathrm{M})$ and incubated for $48 \mathrm{~h}$. After trypsinization, the cells were collected and centrifuged at $800 \times g$ for $15 \mathrm{~min}$. They were then fixed in ice-cold $70 \%$ ethanol overnight at $-20{ }^{\circ} \mathrm{C}$. The fixed cells were centrifuged at $800 \times \mathrm{g}$ for $15 \mathrm{~min}$ and stained with $50 \mu \mathrm{g} / \mathrm{mL}$ PI, containing $50 \mu \mathrm{g} / \mathrm{mL}$ DNase-free RNase A, at $37^{\circ} \mathrm{C}$ for $30 \mathrm{~min}$. The DNA content of the cells (10,000 cells) was analyzed by flow cytometer at $488 \mathrm{~nm}$, using a FACSCalibur flow cytometer (BD Biosciences, San Jose, CA, USA).

\subsubsection{Annexin V/PI Apoptotic Assay}

Flow cytometry using Annexin $\mathrm{V}$ and propidium iodide (PI) was performed in order to detect apoptotic cell death. MCF-7 cells were seeded at a density of $1 \times 10^{5}$ cells/well, treated with the vehicle $(0.1 \%(v / v) \mathrm{EtOH})$ or compound $3 \mathrm{a}(2 \mu \mathrm{M})$, and incubated for $48 \mathrm{~h}$. The cells were then harvested and washed twice in 1X binding buffer, and incubated in the dark for 30 min on ice in Annexin V-containing binding buffer [1:100]. They were then re-suspended in PI-containing binding buffer [1:1000]. The samples were analyzed immediately using a BD Accuri flow cytometer, and GraphPad Prism software version 5.01 was used to analyze the data. Four populations were identified during the assay: Annexin V-negative and PI-negative (Q4, healthy cells), Annexin V-positive and PI-negative (Q3, early apoptosis), Annexin V-positive and PI-positive (Q2, late apoptosis), and Annexin V-negative and PI-positive (Q1, necrosis).

\subsubsection{Zebrafish Embryo Treatments}

The zebrafish embryos were obtained by natural pairwise breeding, and were treated essentially as described previously [29].

The compounds were dissolved in dimethylsulfoxide (DMSO) in order to prepare a stock concentration of $10 \mathrm{mM}$. The embryos treated with $0.10 \%$ DMSO $(v / v)$ served as the negative controls. 


\subsubsection{Imaging and Microscopy}

A Zeiss Observer D1 inverted microscope using Zeiss ZEN software was used to capture the images of the live zebrafish embryos.

Wild-type zebrafish were maintained at $28.5^{\circ} \mathrm{C}$ in a $10 \mathrm{~h}$ dark and $14 \mathrm{~h}$ light period in a circulating water system provided by Pentair (www.pentair.com). The fish were kept following the national and international guidelines for the care and use of laboratory animals. The fertilized eggs were obtained by the natural pairwise breeding of adult fish. The approval of the Ethics Committee for the use and care of laboratory animals was not needed, as zebrafish larvae less than 5 days post fertilization were used [30].

A stock solution of $50 \mathrm{mM}$ was prepared by dissolving the compounds in dimethyl sulfoxide (DMSO). At least 30 fertilized eggs were sorted and placed in $60-\mathrm{mm}$ sterile glass Petri dishes. A serial dilution of the compounds was prepared by adding the required amount of the compound directly into $5 \mathrm{~mL}$ water, and the zebrafish embryos were then exposed to serial dilutions ( 0.5 to $1000 \mu \mathrm{M}$ ) of each compound overnight. The number of dead and living embryos were counted after the overnight exposure.

\section{Conclusions}

All the synthesized s-triazine dipeptides derivatives showed some biological activity, compound 3a (Methyl (4-morpholino-6-(phenylamino)-1, 3, 5-triazin-2-yl) glycylglycinate) was identified as a novel potent anticancer agent. Compounds 3 a showed excellent activity against the MCF-7and MDA-MB-231 cancer cell lines, with IC $_{50}$ values of 0.82 and $9.36 \mu \mathrm{M}$, respectively, compared to the reference drug tamoxifen $\left(\mathrm{IC}_{50}=5.12\right.$ and $15.01 \mu \mathrm{M}$ in MCF-7 and MDA-MB-231 cells, respectively). This can be an indication of certain selectivity in front of those cells that overexpress estrogen and progesterone receptors. In addition, 3a showed some selectivity for the cancer cells, since the $\mathrm{IC}_{50}$ against non-tumorigenic HEK-293 cells was higher than $50 \mu \mathrm{M}$, which represents almost two orders of magnitude of difference. The in vivo studies using zebrafish embryos confirmed the low toxicity of compound 3a. In this regard, up to a concentration of $1 \mathrm{mM}$, this compound showed the same mortality ratio as the control. Furthermore, the images of the treated embryos did not indicate any embryonic abnormality or morphological difference compared with the untreated embryos.

Finally, the study of the MCF-7 cell cycle revealed that compound 3a arrests the cycle in the G2/M phase, which is associated with enhanced apoptosis. This finding was demonstrated in the Annexin V/PI apoptotic assay.

Given the in vitro and in vivo results, we can conclude that compound $3 a$ could be considered "hits" for further investigation and derivatization. In a posterior work, it will be fined tune-up and then will studied deeply to determine its mechanism of action and interaction with protein targets in human breast cancer cells.

Supplementary Materials: The following are available online. Figures S1-S15: the ${ }^{1} \mathrm{H}$ and ${ }^{13} \mathrm{C}-\mathrm{NMR}$ spectrum for the prepared compounds $3 \mathbf{a}-\mathbf{0}$.

Author Contributions: The work was supervised and designed by A.E.-F., Z.A., B.G.d.l.T., and F.A. The synthesis and characterization were carried out R.A.A., Z.A. and A.S., A.M.M., M.F. and M.A.M.W. performed the biological studies. All of the authors discussed the results. R.A.A., Z.A. and A.S. prepared the first drafts of the manuscript. The final version included contributions from all of the authors. All authors have read and agreed to the published version of the manuscript.

Funding: The work was funded in part by the National Research Foundation (NRF) (\# 105892 and Blue Sky's Research Programme \# 120386). This study was funded by the Deanship of Scientific Research, King Saud University, through the Vice Deanship of Scientific Research Chairs.

Institutional Review Board Statement: Not applicable.

Conflicts of Interest: The authors declare no conflict of interest.

Sample Availability: The data presented in this study are available in this article or supplementary material here. 


\section{References}

1. Fisher, C.S.; Wachtel, M.S.; Margenthaler, J.A. Outcomes for Patients who Develop Both Breast and Colorectal Cancer. Ann. Surg. Oncol. 2011, 19, 242-248. [CrossRef]

2. Jordan, V.C. Tamoxifen as the first targeted long-term adjuvant therapy for breast cancer. Endocrine-Related Cancer 2014, 21, R235-R246. [CrossRef]

3. Katzenellenbogen, J.A.; Mayne, C.G.; Katzenellenbogen, B.S.; Greene, G.L.; Chandarlapaty, S. Structural underpinnings of oestrogen receptor mutations in endocrine therapy resistance. Nat. Rev. Cancer 2018, 18, 377-388. [CrossRef]

4. Riggins, R.B.; Schrecengost, R.S.; Guerrero, M.S.; Bouton, A.H. Pathways to tamoxifen resistance. Cancer Lett. 2007, 256, 1-24. [CrossRef] [PubMed]

5. Bhusnure, O.G.; Mane, J.M.; Gholve, S.B. Drug Target Screening and its Validation by Zebrafish as a Novel Tool. Pharm. Anal. Acta 2015, 6, 1-9. [CrossRef]

6. Macrae, C.A.; Peterson, R.T. Zebrafish as tools for drug discovery. Nat. Rev. Drug Discov. 2015, 14, 721-731. [CrossRef] [PubMed]

7. Sieber, S.; Grossen, P.; Bussmann, J.; Campbell, F.; Kros, A.; Witzigmann, D.; Huwyler, J. Zebrafish as a preclinical in vivo screening model for nanomedicines. Adv. Drug Deliv. Rev. 2019, 151-152, 152-168. [CrossRef]

8. Katoch, S.; Patial, V. Zebrafish: An emerging model system to study liver diseases and related drug discovery. J. Appl. Toxicol. 2021, 41, 33-51. [CrossRef] [PubMed]

9. Lieschke, G.J.; Currie, P.D. Animal models of human disease: zebrafish swim into view. Nat. Rev. Genet. 2007, 8, 353-367. [CrossRef]

10. Shah, D.R.; Modh, R.P.; Chikhalia, K.H. Privileged s-triazines: structure and pharmacological applications. Futur. Med. Chem. 2014, 6, 463-477. [CrossRef]

11. Singla, P.; Luxami, V.; Paul, K. Triazine as a promising scaffold for its versatile biological behavior. Eur. J. Med. Chem. 2015, 102, 39-57. [CrossRef]

12. Sharma, A.; El-Faham, A.; De La Torre, B.G.; Albericio, F. Exploring the Orthogonal Chemoselectivity of 2,4,6-Trichloro-1,3,5Triazine (TCT) as a Trifunctional Linker With Different Nucleophiles: Rules of the Game. Front. Chem. 2018, 6, 516. [CrossRef]

13. Sharma, A.; Sheyi, R.; Kumar, A.; El-Faham, A.; De La Torre, B.G.; Albericio, F. Investigating Triorthogonal Chemoselectivity. Effect of Azide Substitution on the Triazine Core. Org. Lett. 2019, 21, 7888-7892. [CrossRef]

14. Abd Alhameed, R.; Almarhoon, Z.; Sholkamy, N.E.; Ali Khan, S.; Ul-Hag, Z.; Sharma, A.; de la Torre, B.G.; Albericio, F.; El-Faham, A. Novel 4,6-Disubstituted s-Triazin-2-yl Amino Acid Derivatives as Promising Antifungal Agents. J. Fungi 2020, 6, 237. [CrossRef]

15. El-Faham, A.; Farooq, M.; Almarhoon, Z.; Alhameed, R.A.; Wadaan, M.A.; de la Torre, B.G.; Albericio, F. Di- and tri-substituted s-triazine derivatives: Synthesis, characterization, anticancer activity in human breast-cancer cell lines, and developmental toxicity in zebrafish embryos. Bioorganic Chem. 2020, 94, 103397. [CrossRef] [PubMed]

16. Barakat, A.; El-Senduny, F.F.; Almarhoon, Z.; Al-Rasheed, H.H.; Badria, F.A.; Al-Majid, A.M.; Ghabbour, H.A.; El-Faham, A. Synthesis, X-Ray Crystal Structures, and Preliminary Antiproliferative Activities of New s-Triazine-hydroxybenzylidene Hydrazone Derivatives. J. Chem. 2019, 2019, 1-10. [CrossRef]

17. Sunduru, N.; Gupta, L.; Chaturvedi, V.; Dwivedi, R.; Sinha, S.; Chauhan, P.M. Discovery of new 1,3,5-triazine scaffolds with potent activity against Mycobacterium tuberculosis H37Rv. Eur. J. Med. Chem. 2010, 45, 3335-3345. [CrossRef] [PubMed]

18. Patel, R.V.; Kumari, P.; Rajani, D.P.; Pannecouque, C.; de Clercq, E.; Chikhalia, K.H. Antimicrobial, anti-TB, anticancer and anti-HIV evaluation of new s-triazine-based heterocycles. Future Med. Chem. 2012, 4, 1053-1065. [CrossRef] [PubMed]

19. Khattab, S.N.; Khalil, H.H.; Bekhit, A.A.; El-Rahman, M.M.A.; El-Faham, A.; Albericio, F. Synthesis and Preliminary Biological Evaluation of 1,3,5-Triazine Amino Acid Derivatives to Study Their MAO Inhibitors. Molecules 2015, 20, 15976-15988. [CrossRef]

20. Maira, S.-M.; Pecchi, S.; Huang, A.; Burger, M.; Knapp, M.; Sterker, D.; Schnell, C.; Guthy, D.; Nagel, T.; Wiesmann, M.; et al. Identification and Characterization of NVP-BKM120, an Orally Available Pan-Class I PI3-Kinase Inhibitor. Mol. Cancer Ther. 2012, 11,317-328. [CrossRef]

21. Kong, D.; Yamori, T. ZSTK474 is an ATP-competitive inhibitor of class I phosphatidylinositol 3 kinase isoforms. Cancer Sci. 2007, 98, 1638-1642. [CrossRef]

22. Zheng, M.; Xu, C.; Ma, J.; Sun, Y.; Du, F.; Liu, H.; Lin, L.; Li, C.; Ding, J.; Chen, K.; et al. Synthesis and antitumor evaluation of a novel series of triaminotriazine derivatives. Bioorg. Med. Chem. 2007, 15, 1815-1827. [CrossRef] [PubMed]

23. Al Rasheed, H.H.; Malebari, A.M.; Dahlous Kh., A.; El-Faham, A. Synthesis and characterization of new series of 1,3-5-triazine hydrazone derivatives with promising anti-proliferative activity. Molecules 2020, 25, 2708. [CrossRef] [PubMed]

24. El-Faham, A.; Al Marhoon, Z.; Abdel-Megeed, A.; Albericio, F. OxymaPure/DIC: An Efficient Reagent for the Synthesis of a Novel Series of 4-[2-(2-Acetylaminophenyl)-2-oxo-acetylamino] Benzoyl Amino Acid Ester Derivatives. Molecules 2013, 18, 14747-14759. [CrossRef] [PubMed]

25. Aggelis, V.; Johnston, S.R.D. Advances in Endocrine-Based Therapies for Estrogen Receptor-Positive Metastatic Breast Cancer. Drugs 2019, 79, 1849-1866. [CrossRef] [PubMed]

26. Jordan, V.C. The SERM Saga, Something from Nothing: American Cancer Society/SSO Basic Science Lecture. Ann. Surg. Oncol. 2019, 26, 1981-1990. [CrossRef]

27. Xia, L.; Zheng, L.; Zhou, J.L. Transcriptional and morphological effects of tamoxifen on the early development of zebrafish (Danio rerio). J. Appl. Toxicol. 2016, 36, 853-862. [CrossRef] 
28. Yu, Q.; Huo, J.; Zhang, Y.; Liu, K.; Cai, Y.; Xiang, T.; Jiang, Z.; Zhang, L. Tamoxifen-induced hepatotoxicity via lipid accumulation and inflammation in zebrafish. Chemosphere 2020, 239, 124705. [CrossRef]

29. Farooq, M.; Al Marhoon, Z.M.; Taha, N.A.; Baabbad, A.A.; Al-Wadaan, M.A.; El-Faham, A. Synthesis of Novel Class of N-Alkylisatin-3-iminobenzoic Acid Derivatives and Their Biological Activity in Zebrafish Embryos and Human Cancer Cell Lines. Biol. Pharm. Bull. 2018, 41, 350-359. [CrossRef] [PubMed]

30. Strähle, U.; Scholz, S.; Geisler, R.; Greiner, P.; Hollert, H.; Rastegar, S.; Schumacher, A.; Selderslaghs, I.; Weiss, C.; Witters, H.; et al. Zebrafish embryos as an alternative to animal experiments-A commentary on the definition of the onset of protected life stages in animal welfare regulations. Reprod. Toxicol. 2012, 33, 128-132. [CrossRef] 